Revista de Psicología Vol. 33 (2), 2015 (ISSN 0254-9247)

\title{
Estudio del impacto de imágenes ambientales en los aspectos emocionales
}

\author{
Martha Patricia Sánchez Miranda ${ }^{1}$ y Arturo de la Garza González ${ }^{2}$ \\ Universidad Autónoma de Nuevo León
}

La presente investigación examinó las emociones que desencadenan imágenes de naturaleza y ciudad de forma automática e implícita con la técnica de facilitación afectiva y determinar si el mismo fenómeno que se ha estudiado en experimentos unimodales se repite en la modalidad cruzada. Participaron un total de 57 estudiantes de una universidad pública mexicana, donde se les expuso a imágenes de ambientes naturales y urbanos como facilitadores. Como objetivos se utilizaron palabras con connotación emocional positiva y negativa. Los resultados indican que al igual que en otras investigaciones, existen dos grupos de participantes, en donde no todos poseen emociones positivas hacia la naturaleza. Se discuten los resultados en términos de los mecanismos cognitivos que existen dentro de la técnica.

Palabras clave: ambiente natural, ambiente urbano, facilitación afectiva, unimodal, modalidad cruzada.

\section{Study of the impact of environmental pictures on emotional aspects}

The present research examined emotions that automatically and implicitly trigger pictures of nature and the city, with the affective priming technique, and determined if the same phenomenon that has been studied in unimodal experiments was replicated in cross modality experiments. The sample included 57 psychology students from a Mexican public university who were exposed to images of natural and urban environments. They used words with positive and negative emotional connotations. The results are similar to other research studies, and indicate that there are two types of participants, and not all participants displayed positive emotions towards nature. The findings are discussed in terms of the cognitive mechanisms of the technique.

Keywords: natural environment, urban environment, affective priming, unimodal, cross modality

1 Doctora en Psicología y profesora investigadora de la UANL, es miembro del sistema nacional de investigadores de México. Dirección postal: Dr. Carlos Canseco \#110 y Dr. Eduardo Aguirre Pequeño, col. Mitras Centro, Monterrey, Nuevo León, México. C.P. 64460. Contacto: marpa30@gmail.com

2 Ingeniero en computación y asistente de investigación de la UANL, es programador de sistemas expertos. Contacto: agarza7@gmail.com 
A finales de los años 40's y principios de los 60's se sientan las bases para los primeros grupos del movimiento ambiental gracias a los trabajos de Leopold y Carson en una incansable búsqueda de la preservación de los espacios naturales (Garza, 2009; Knight \& Reidel, 2002). Sin embargo, a la fecha este movimiento no ha terminado, y aunque en múltiples estudios existentes sobre la conservación del entorno natural se reconoce la importancia de preservar la naturaleza, las conductas de destrucción siguen presentes en la mayoría de los miembros de la sociedad. Preocupados por entender el comportamiento del ser humano en su ambiente, se han desarrollado investigaciones sobre las actitudes que las personas poseen del ambiente utilizando instrumentos explícitos, es decir, autoreportes, donde el participante indica qué tan de acuerdo se encuentra con una serie de enunciados. Los resultados obtenidos indican que la mayoría de las personas poseen una actitud positiva hacia el ambiente y tratarán de conservarlo ya sea por argumentos antropocéntricos, egocéntricos y/o biosféricos (Dietz, Stern \& Guagnano, 1998; Schultz \& Zelezny, 2003).

En este tipo de mediciones, la mayoría de los grupos estudiados poseen una actitud y valoración positiva hacia el ambiente (Amérigo, Aragonés, De Frutos, Sevillano \& Cortés, 2007; González \& Amérigo, 1999; Hernández, Suarez, Martínez-Tovisco \& Hess, 1997; Milfont, 2010; Pato, Ros \& Tamayo, 2005; Schultz, 2002; Tacáks-Sánta, 2007; Vozmediano \& Guillén, 2005). Sin embargo, estos resultados pueden ser causados por los sesgos que desencadena la deseabilidad social, la cual se entiende como la tendencia que tienen los participantes a dar respuestas que están de acuerdo a lo que la sociedad considera como adecuado (Greenwald, 1990; Sintov \& Prescott, 2011).

En la búsqueda de alternativas que permitan disminuir esta deseabilidad social se han elaborado instrumentos implícitos, es decir, mediciones en donde los participantes no están conscientes de sus 
respuestas y por lo tanto no son fácilmente elaboradas a voluntad. Entre este tipo de mediciones se encuentran las elaboradas con el paradigma de facilitación afectiva. Esta resulta de interés ya que permite conocer con más detalle las emociones que desencadenan los diversos ambientes. Esto permite contrastar la gran cantidad de artículos con estudios explícitos que indican actitudes positivas y por lo tanto emociones que favorecen el cuidado del ambiente, pero que no se refleja en conductas acordes a estos resultados. Existen algunas investigaciones implícitas donde se obtienen resultados similares a los autoreportes, los cuales se retomarán más adelante (Hietanen, Klemettilä, Kettunen \& Korpela, 2007; Hietanen \& Korpela, 2004; Korpela, Klemettilä \& Hietanen, 2002; Sánchez, De la Garza \& López, 2009; Schultz, Shriver, Tabanico \& Khazian, 2004).

\section{Facilitación Afectiva}

La facilitación afectiva se encuentra sustentada en la facilitación semántica, dentro de este paradigma se asume que la información se encuentra organizada en la memoria a largo plazo en forma de redes, donde cada nodo se relaciona entre sí mediante una serie de conceptos. Se puede llegar a conocer la cercanía o proximidad de dos conceptos utilizando la técnica de facilitación semántica o afectiva (Fazio \& Olson, 2003). De esta manera, un estímulo facilitador es presentado por un espacio de 250 milisegundos (ms), seguido de una pantalla en blanco por $50 \mathrm{~ms}$, y seguido a su vez por el estímulo objetivo, el cual permiten que se active la red de conceptos que hay alrededor de él. Si existe relación de la valencia emocional o semántica entre ambos conceptos, los tiempos de reacción serán bajos, de lo contrario los tiempos serán altos (Morales, López \& Hedlefs, 2010).

Dentro de este paradigma se han propuesto varias explicaciones teóricas, para lo cual se han desarrollado diferentes mecanismos que permiten su comprensión. Uno de ellos es el difusión de la activación, el cual plantea que al presentar un estímulo, este promueve la activación de 
la red, propagándose entre los diferentes conceptos que lo componen. Al llegar a aquel concepto o nodo que se encuentra asociado a dicho facilitador, permitiría la respuesta de acuerdo a dicha asociación. En el caso de la facilitación afectiva, la asociación se realiza al en contrarse con la misma valencia emocional, positiva o negativa, en los pares de estímulos presentados (Pecchinenda, Ganteaume \& Banse, 2006).

Por otro lado, existe una propuesta alternativa para explicar la facilitación afectiva denominado competencia de respuesta. Está basada en la tarea de Stroop y consiste en ignorar parcialmente cierta información, permitiendo con ello activar unidades que faciliten la respuesta a objetivos congruentes o interfiriendo con respuestas a objetivos incongruentes (Klauer \& Musch, 2003). Así, bajo este mecanismo también es común encontrar que al realizar la tarea, se activan unidades de respuestas que van a permitir realizar la evaluación correcta de los pares de estímulos congruentes e interferir con los incongruentes. Por ejemplo, al presentar un facilitador con una valencia positiva y un objetivo con valencia negativa el participante debe ignorar el primer estímulo, es decir el facilitador, y decidir sobre el segundo estímulo, el objetivo, ocasionando que la inhibición del primer estímulo incremente los tiempos de reacción, que cuando se presentan estímulos congruentes.

Existe una tercera propuesta llamada mecanismo de coincidencias afectivas. En esta se asume que existe un sesgo en las respuestas al momento de decidir que la elección es afirmativa. Supone que las emociones son desencadenados por la coincidencia de la valencia entre los estímulos facilitador y objetivo. Así, las decisiones negativas ocurren cuando existe la imposibilidad de que los facilitadores produzcan emociones de valencias que coinciden con los objetivos (Eder, Hommel \& De Houwer, 2007).

De acuerdo a estos mecanismos, se acepta que las evaluaciones se activan de forma espontánea y automática. Es decir, aun y cuando la tarea se hace de forma consciente, decidir si el objetivo posee una valencia emocional o no, depende de la relación entre el facilitador y el objetivo la cual no es consciente, además de que se realiza de manera muy rápida (Moors, Spruy \& De Houwer, 2010). 


\section{Modalidad cruzada}

Es común encontrar que dentro de los estudios de facilitación afectiva se realicen diseños unimodales, en donde los pares de estímulos pertenecen al mismo tipo de representación, por ejemplo, donde facilitador y objetivos son palabras o imágenes. Existe una preferencia en la técnica por utilizar pares de palabras sobre las imágenes, con el argumento que utilizar este tipo de estímulos la codificación semántica (lexical) se almacena mejor que otro tipo de información (Bajo, 1988). Sin embargo, otros investigadores se han inclinado por el uso de imágenes bajo la premisa de que estas permiten usar un código métrico y espacial que es más parecido al perceptual, haciendo más fácil la recuperación de la información de la memoria a largo plazo (Stenberg, Radeborgd \& Hedman, 1995).

Existe también otro tipo de diseño denominado modalidad cruzada, llamados así por utilizar estímulos facilitadores y objetivos que utilizan diferentes representaciones, como imágenes y palabras. También pueden utilizar información perceptual de diferente tipo como puede ser visual y auditiva (De Vega, 1984; Schneider, Engel \& Debener, 2008).

Los investigadores que utilizan este tipo de modalidad proponen que la codificación de la información es dual, ya que ambos códigos interactúan, permitiendo que la información se almacene y se recupere mejor. Paivio, Clark, Digdon y Bons (1989) han encontrado que al utilizar diseños con pares de imágenes-palabras se obtienen resultados similares a los de palabra-palabra o imágenes-imágenes. Además, Schneider y colaboradores (2008) mencionan que en la vida cotidiana recibimos información desde diferentes sentidos los cuales procesamos, codificamos y tomamos decisiones, motivo por el cual es importante tomar en cuenta los diferentes tipos estímulos al momento de realizar un estudio de facilitación. 


\section{Medidas implícitas ambientales}

Se han desarrollado investigaciones con mediciones implícitas, como los trabajos que estudian la actitud e identidad en el ámbito ambiental a través de las pruebas de asociación implícita (IAT de sus siglas en inglés: Implicit Association Test). Estas pruebas comenzaron a efectuarse desde principios del año 2000 y entre las investigaciones realizadas se encuentran las de Schultz y colaboradores (2004), cuyos resultados muestran una tendencia a la identificación con la naturaleza. También Olivos y Aragonés (2013) encontraron resultados similares: una identidad hacia entornos naturales. Sin embargo, al indagar sobre la validez predictiva junto con otras pruebas, no se obtuvieron buenos resultados. Con respecto a la identidad y actitud implícita, Sánchez, De la Garza y López $(2009,2010)$, realizaron una prueba del IAT y encontraron que dentro de la misma muestra existen dos tipos de grupos. Uno que representa a la mayoría de los participantes y que poseen una identidad y actitud positiva hacia los entornos naturales, y un segundo que, siendo minoría, poseen una identidad y actitud positiva hacia el entorno urbano.

Fazio (2001), siguiendo las ideas del paradigma de facilitación semántica, propone que al presentar los facilitadores estos actúan como los objetos de actitud y los objetivos son los que desencadenan la valoración positiva o negativa, lo cual sería la actitud. Con esta técnica se han efectuado trabajos relacionados a entornos naturales y construidos, detectando una actitud positiva hacia los entornos naturales, utilizando tanto facilitaciones unimodales imagen-imagen (Hietanen et al., 2007; Hietanen \& Korpela, 2004). Así también de modalidad cruzada de imagen-audio, donde los tiempos de reacción fueron más rápidos para las expresiones vocales de alegría con facilitadores de naturaleza restaurativas, que para los facilitadores de imágenes urbanas poco restaurativas (Korpela et al., 2002). Cabe destacar que en el trabajo de Hietanen y colaboradores (2004) ellos encontraron una tendencia a responder a las imágenes con un nivel de restauración alta con felicidad; sin embargo, el efecto no lo confirma ya que su medidas de control parecen no 
poseer esta característica. Por otro lado, en el estudio de Hietanen y colaboradores (2007), al modificar un mismo escenario incrementado los elementos naturales o los construidos, los tiempos de reacción son menores para los rostros que denotan felicidad cuando en los escenarios se incrementan los elementos naturales.

En otro estudio, Sánchez, De la Garza y Rangel (2013) encontraron a través de una prueba unimodal (palabra-palabra) que al igual que las pruebas de asociación implícita, existen dos grupos dentro de la muestra por el tiempo de reacción a las palabras facilitadoras positivas relacionadas a la naturaleza. De esta forma, existe un grupo que reacciona de forma positiva a los entornos naturales positivos y otro grupo que reacciona a estos mismos estímulos de manera negativa.

Ante estos resultados de identidad y actitud positiva hacia el ambiente natural algunos investigadores han retomado la hipótesis de la biofilia propuesta por Edward Wilson, como una alternativa de explicación a dichos resultados (Sánchez et al., 2009, 2010; Schultz et al., 2004). La biofilia se entiende como la conexión innata que los seres humanos poseen hacia todos los seres vivos y entornos naturales. Está conexión involucra aspectos emocionales, morales y cognitivos (Wilson, 1999). Argumenta que como nuestra especie evolucionó en espacios naturales, todas estas habilidades psicológicas le proporcionaron información del entorno que le permitían sobrevivir. Algo a tener en cuenta es que aun y cuando en la actualidad los seres humanos no están tanto en contacto con la naturaleza, estas habilidades siguen presentes.

Así, con el propósito de indagar sobre los aspectos emocionales que desencadenan imágenes de diferentes ambientes, y determinar si se manifiesta el mismo fenómeno en la modalidad cruzada que los encontrados en la unimodal, se plantearon las siguientes hipótesis: a) si las imágenes de ambientes naturales positivos desencadenan emociones de la misma valencia, esta se deberá manifestar en tiempos de respuesta menores hacia palabras objetivo de emociones positivas; $y$ b) si el efecto en la modalidad cruzada es semejante a la unimodal, este se deberá manifestar en el patrón de respuestas semejante para las diferentes condiciones experimentales. 


\section{Método}

Esta investigación tiene un diseño cuasi-experimental, cuenta con tres factores, dos de los cuales pertenecen al facilitador. El primero es el ambiente que posee tres niveles, estas son imágenes de naturaleza, ciudad y neutros (N, C, NU). El segundo es la valencia de estas imágenes, las cuales pueden ser positivas, negativas y neutras ( $\mathrm{P}, \mathrm{N}$ y NU). El último factor es el objetivo, los cuales son palabras emocionales que tienen tres tipos de valencia, que pueden ser positivos, negativos y neutros (véase la Tabla 1 ).

\section{Tabla 1}

Combinaciones de las condiciones experimentales del diseño factorial $3 \times 2$ $\times 3$ utilizadas en el estudio.

\begin{tabular}{|c|c|c|c|c|c|c|}
\hline \multirow[b]{3}{*}{ Objetivo } & \multicolumn{6}{|c|}{ Facilitador } \\
\hline & \multicolumn{2}{|c|}{ Naturaleza (N) } & \multicolumn{2}{|c|}{ Ciudad (C) } & \multicolumn{2}{|c|}{ Neutro (NU) } \\
\hline & $\operatorname{POS}(\mathrm{P})$ & NEG(N) & $\operatorname{POS}(\mathrm{P})$ & NEG(N) & NEU(NU) & NEU(NU) \\
\hline $\operatorname{POS}(\mathrm{P})$ & NP-P & NN-P & CP-P & $\mathrm{CN}-\mathrm{P}$ & NU-P & NU-P \\
\hline NEG(N) & NP-N & NN-N & $\mathrm{CP}-\mathrm{N}$ & $\mathrm{CN}-\mathrm{N}$ & NU-N & NU-N \\
\hline NEU(NU) & NP-NU & NN-NU & $\mathrm{CP}-\mathrm{NU}$ & CN-NU & NU-NU & NU-NU \\
\hline
\end{tabular}

Nota $: \operatorname{POS}(\mathrm{P})=$ positiva, $\mathrm{NEG}(\mathrm{N})=$ negativa, $\mathrm{NEU}(\mathrm{NU})=$ neutro, $\mathrm{NP}=$ naturaleza positiva, $\mathrm{NN}=$ naturaleza negativa, $\mathrm{CP}=$ ciudad positiva, $\mathrm{CN}=$ ciudad negativa, $\mathrm{NU}=$ neutro. Los primeros caracteres antes del guion son el facilitador con la combinación de ambiente y valencia, después está el tipo de objetivo. Los facilitadores neutros no tienen valencia y se repiten dos veces para balancear la cantidad de estímulos de ciudad y naturaleza.

\section{Participantes}

En el estudio participaron 57 estudiantes de una escuela de psicología de una universidad pública de México. El tipo de muestra es de conveniencia y no probabilística. Tienen las mismas características en cuanto a nivel socio económico, además de vivir en la misma ciudad. 
Los promedios de edad fueron de 18.1 años y los sexos tienen una distribución de $47.3 \%$ de hombres y $52.7 \%$ de mujeres.

Los criterios de exclusión que se utilizaron fueron los mismos que se han utilizado en estudios previos (Sánchez et al., 2013), los cuales consistieron en eliminar a los sujetos que excedieron el 20\% de errores en el estudio. Además, también aquellos que superan los $1000 \mathrm{~ms}$ en promedio en la aplicación del instrumento. Las respuestas individuales que excedían los 1500ms y los que estaban equivocadas fueron sustituidas por la media de su respectiva condición experimental. Después de aplicar estos criterios se obtuvieron un total de 52 sujetos para el análisis.

\section{Medidas e instrumentos de medición}

El instrumento utilizado se implementó a través de un programa informático desarrollado en Visual Studio. Se utilizaron computadoras portátiles con sistema operativo Windows 7 , con pantallas de 14 pulgadas de tamańo. Se ajustó la intensidad de brillo en todas ellas al mismo nivel. La técnica consistió en presentar tres estímulos consecutivos, los cuales fueron: primero un punto de fijación en el centro de la pantalla por espacio de $500 \mathrm{~ms}$. Inmediatamente después aparece una imagen por un tiempo de $250 \mathrm{~ms}$ que actúa como facilitador, seguida por una pantalla en blanco por $50 \mathrm{~ms}$, a esta presentación de $300 \mathrm{~ms}$ se le denomina SOA (de sus siglas en inglés stimulus onset asynchrony). Al final se muestra una palabra que es el estímulo objetivo, sobre la cual los sujetos deben decidir si poseen contenido emocional o no. Esta última palabra permanece en pantalla hasta que exista una respuesta de parte del participante (Figura 1). Los tiempos son los utilizados en investigaciones previas (Morales et al., 2010). 


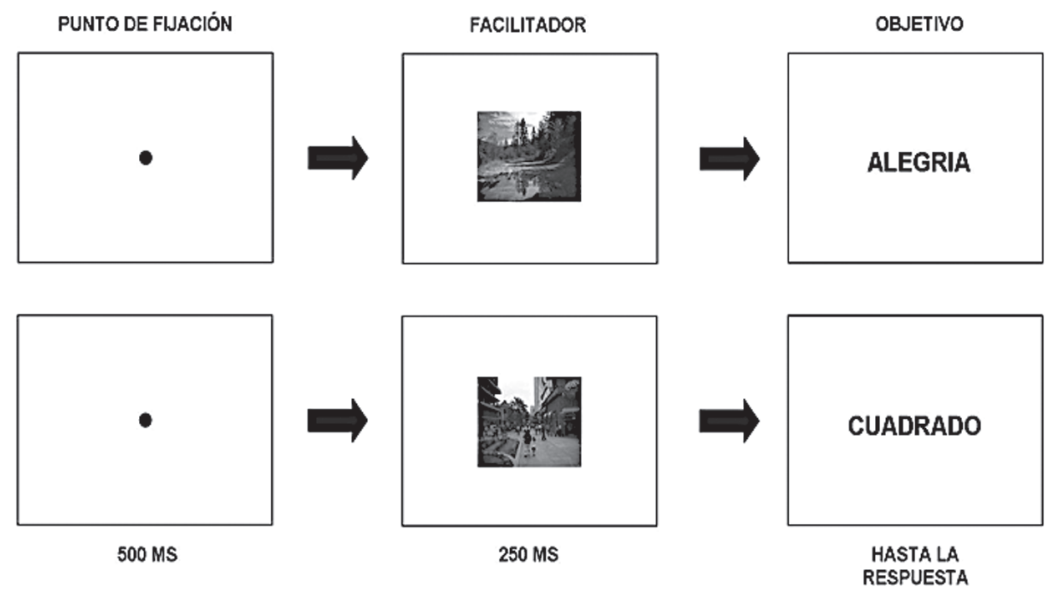

Figura 1. Ejemplos de la secuencia de pantallas presentadas en el estudio (no se ilustra la pantalla en blanco).

Los estímulos facilitadores consistieron en imágenes de ambientes tanto de ciudad como de naturaleza. Se retomaron del estudio realizado por Sánchez, De la Garza, López y Morales (2012), que consistió en presentar una serie de imágenes de ambientes de naturaleza y ciudad, las cuales fueron valorados por los participantes en una escala Likert de acuerdo al grado de relación que sentían con ellas. También se incluyeron imágenes de figuras geométricas como una forma de control experimental. Se mantuvieron las mismas proporciones en el tipo imagen y su valencia para mantener un equilibro en el estudio.

Para los estímulos objetivos se utilizaron palabras con contenido emocional, las cuales tenían tanto valencia positiva como negativa. Estas palabras fueron utilizadas en el estudio realizado por Sánchez y colaboradores (2013). Además, se emplearon los nombres de figuras geométricas como estímulos neutros, ya que no contienen valencia emocional (ver Tabla 2). Todas ellas se mostraron en las mismas cantidades con la finalidad de guardar un equilibro en el diseño del instrumento. 


\section{Tabla 2}

Palabras empleadas como estimulos objetivo.

\begin{tabular}{lll}
\hline POSITIVAS (P) & NEGATIVAS (N) & NEUTRAS (NU) \\
\hline Amor & Miedo & Cruz \\
Serenidad & Tristeza & Estrella \\
Optimismo & Odio & Triángulo \\
Triunfo & Temor & Círculo \\
Felicidad & Fastidio & Cuadrado \\
\hline
\end{tabular}

\section{Procedimiento}

Los estudiantes fueron invitados para que participaran de forma voluntaria en la investigación, informándoles la finalidad del estudio, así como el procedimiento que se iba a seguir (véase anexo A). Los que estuvieron de acuerdo fueron llevados a un cuarto con un mínimo de distractores. Se les pidió que eligieran una computadora y se inició con las instrucciones que debían seguir. Se explicó que verían un punto en el centro de la pantalla por un breve espacio de tiempo, seguido de una imagen la cual solo deberían observar e inmediatamente después aparecería una palabra sobre la que debería decidir si contenía significado emocional o no. Si su respuesta era negativa, ellos debería oprimir la etiqueta azul con la leyenda NO, la cual se encontraba encima de la tecla Z. En caso de que su respuesta fuera afirmativa, se les pidió que oprimieran la etiqueta amarilla SI, que se encontraba en la tecla M. Se les pidió que sus respuestas fueran lo más rápido posible. Para verificar que entendieron las instrucciones, se les presentaron 10 pares de estímulos como práctica. Si al final de ella no tenían dudas se les pidió que iniciarán el estudio.

La aplicación estuvo distribuida en cinco bloques en donde se repartieron 18 estímulos de pares facilitador-objetivo, todos ellos presentados al azar. Al finalizar cada bloque existía la posibilidad de tomar una tiempo de descanso si así lo requerían. En el diseño del instrumento se cuidó que cada bloque contuviera la misma cantidad de los diferentes tipos estímulos, tanto de facilitadores como objetivos. 


\section{Resultados}

El análisis de los datos se realizó en el programa Statistica versión 10. La significancia de referencia utilizada fue de $p=.01$. Como una de las metas de la investigación fue determinar si los datos obtenidos en la modalidad cruzada era similares a los unimodales (como en el estudio de Sánchez et al., 2013), se realizó una revisión preliminar de los datos para determinar si existían diferencias en las respuestas de los participantes en cuanto a sus tiempos de reacción. Se pudo observar que la muestra tiene dos grupos de sujetos de acuerdo a la diferencia en los tiempos de reacción entre la condición experimental de NP-P y NP-N. Al final se obtuvieron 20 sujetos con tiempos menores para NP-P y 36 con tiempos mayores en esta misma condición. Estos grupos los denominaremos de aquí en adelante verdes y urbanos respectivamente.

Con la finalidad de dar validez estadística a esta clasificación, se hizo un análisis discriminante. Como se puede observar en la Tabla 3, se encontró que la clasificación inicial era la apropiada y que las variables NP-P y NP-N son las adecuadas para realizar la categorización de la muestra en dos grupos.

\section{Tabla 3}

Resultados del análisis discriminante con el método forward stepwise.

\begin{tabular}{lcccccc}
\hline & Wilks & Partial & F-remove & $p$ & Toler. & 1-Toler. \\
\hline NP-N & .7 & .8 & 12.3 & .01 & .6 & .4 \\
NP-P & .8 & .7 & 24.7 & .0 & .2 & .8 \\
NN-P & .6 & .9 & 1.2 & .3 & .3 & .7 \\
NN-N & .6 & .9 & 3.1 & .1 & .3 & .7 \\
\hline
\end{tabular}

Nota: resumen del Análisis Discriminante Paso 5; N de variables en el modelo: 4; Agrupamiento: CAT (2 grupos); Wilks' Lambda: .6 aproximadamente; $F(5.49)=7.4 p<.0$

Asimismo, la distribución final quedó en 20 verdes y 35 urbanos (ver Tabla 4). 


\section{Tabla 4}

Clasificación del análisis discriminante.

\begin{tabular}{lcc}
\hline & VERDES & URBANOS \\
\hline VERDES & 17 & 3 \\
URBANOS & 3 & 32 \\
\hline Total & 20 & 35 \\
\hline
\end{tabular}

Se procedió a realizar un análisis de varianza para diseños mixtos con una combinación de factores de $3 \times 2 \times 3 \times 2$, donde cada uno de ellos representa: ambiente $\mathrm{x}$ valencia $\mathrm{x}$ objetivo $\mathrm{x}$ grupo. En la Figura 2 se observan los resultados para la valencia positiva del facilitador, y se puede detectar que las condiciones NP-P y NP-N, que son los estímulos de naturaleza positivos con los objetivos positivos y negativos, tienen un patrón de respuesta diferente para ambos grupos. Pero para las condiciones CP-P, CP-N, CP-NU, NU-P, NU-N y NU-NU, que corresponde a los facilitadores de ciudad y neutros, las respuestas fueron similares para todos los tipos de objetivos.

En los resultados para los facilitadores con valencia negativa que se muestran en la Figura 3 se puede observar que los patrones de respuestas en ambos grupos fueron semejantes para todas las condiciones. Esto se manifiesta en que las líneas son casi paralelas.

Adicionalmente, se realizó una comparación planeada en las condiciones NP-P y NP-N (facilitadores de naturaleza tanto positivo como negativos con objetivos positivos). Los resultados mostraron que la diferencia de los tiempos de reacción entre los grupos es significativa para ambas condiciones: el valor para NP-P es $F(1.53)=4.9, p=.031 \mathrm{y}$ para NP-N es $F(1.53)=7.3, p=.009$.

Para concluir se puede afirmar que el efecto principal del análisis de ANOVA de $F(4.21)=3.7, p=.006$ se debe al patrón de respuesta observado en las condiciones NP-P y NP-N, ya que en las demás condiciones no se observa ninguna diferencia de importancia en los patrones de respuesta. 


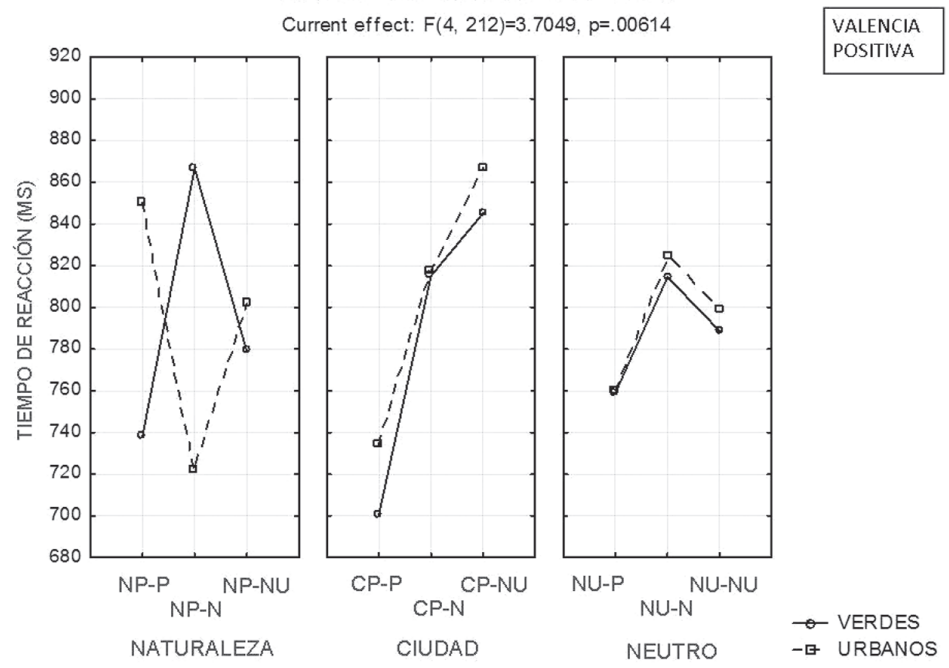

Figura 2. Análisis de varianza para el facilitador con valencia positiva. El tipo de ambiente del facilitador en el eje $\mathrm{x}$ inferior y las combinaciones facilitador-objetivos en la superior, el tipo de línea definen cada grupo.

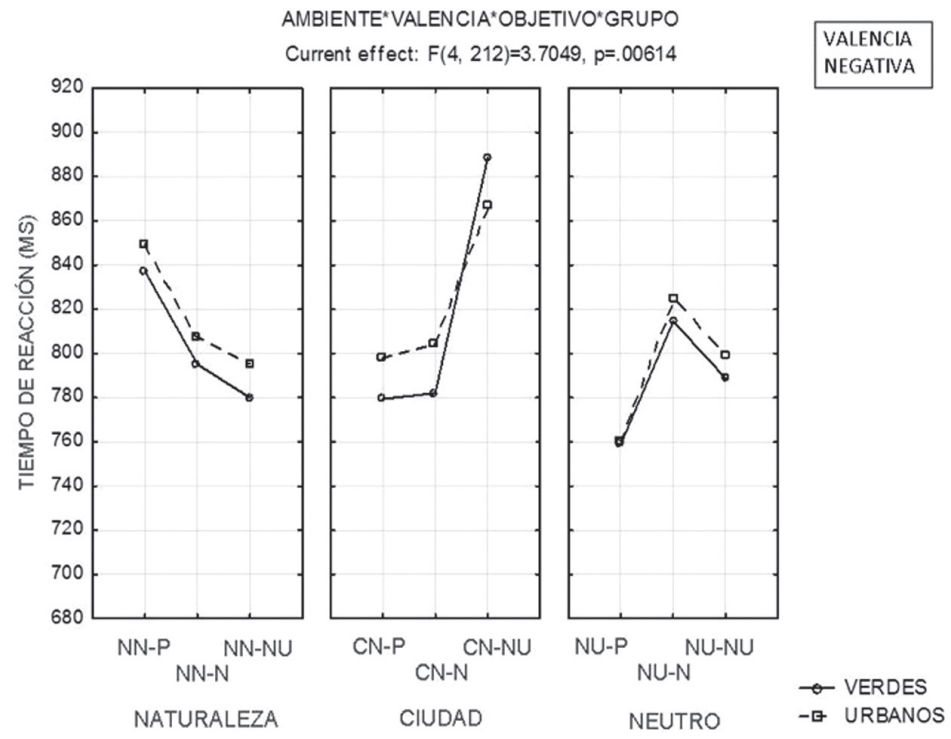

Figura 3. Análisis de varianza para los facilitadores con valencia negativa. 


\section{Discusión}

El presente estudio propone una alternativa de evaluación a través del paradigma de facilitación afectiva con una modalidad cruzada, donde se presenta estímulos de imagen-palabra. En este sentido, la investigación realizada es diferente de los estudios existentes en la literatura que presentan estímulos visual-auditivos (imagen-voz de expresión emocional) y los unimodales con imagen-imagen, y palabra-palabra. Dentro de los resultados se encontró que los tiempos de respuesta para la condiciones de naturaleza positiva mostraron que existe un comportamiento diferenciado dentro de los participantes del estudio. Un grupo de evaluados manifestó tiempos de reacción más bajos para las palabras positivas, pero otro grupo tuvo respuestas en sentido opuesto. Es por esto que no se puede afirmar que las imágenes de naturaleza positiva provoquen tiempos de reacción más bajos para palabras positivas en todos los participantes. Por tal motivo es que queda rechazada la primera hipótesis.

Sin embargo, el resto de condiciones no mostraron este fenómeno, siendo sus tiempos de reacción muy semejantes en ambos grupos. Estos manifiestan un patrón de respuesta semejante a lo que encontraron Sánchez y colaboradores (2013) en su investigación con un diseño unimodal. Por lo tanto la segunda hipótesis queda aceptada.

Además, si se comparan los tiempos para el grupo que llamamos urbano, tanto para los facilitadores de naturaleza positivos como negativos con objetivos positivos (NP-P y NN-P, ver Figuras 2 y 3) sus valores son muy cercanos. Esto nos indica que para ellos no existió un efecto de facilitación y tuvieron la misma respuesta a estas imágenes. Además, cuando las palabras objetivo eran negativas tuvieron tiempos más bajos para ambos tipos de facilitadores (NP-N y NN-N). De esta forma, se puede determinar que ambos tipos de imágenes tienen una valencia negativa para ellos. Esto es algo que cabe resaltar, porque si se observan las imágenes de naturaleza positiva que se utilizan, es difícil explicar cómo es posible faciliten palabras como miedo, tristeza, odio. $\mathrm{Y}$ que al contrario no lo hagan con palabras como amor, serenidad, 
optimismo. Retomando las explicaciones de los mecanismos que subyacen a esta técnica, se puede mencionar que dentro de este paradigma se asume que la información que recibimos a lo largo de la vida se encuentra organizada en forma de redes que se activan al presentarse un estímulo (Fazio \& Olson, 2003). Para explicar dichas activaciones existen diversos mecanismos uno de los más reconocidos es el dispersión de activación (Pecchinenda et al., 2006). Al parecer en este caso, las imágenes de naturaleza tanto positivas como negativas, provocó en el grupo de los urbanos la activación de la red de información que poseen asociándose con información de contenido emocional negativo.

Por otro lado, el grupo denominado verde obtuvo resultados similares a los obtenidos por Korpela y colaboradores (2002), así como Hietanen y colaboradores (2007), donde las imágenes de naturaleza con mayor restauración son asociadas con emociones positivas. En este artículo se trabajó con imágenes con contenido emocional positivo y negativo, con asociaciones congruentes entre el facilitador y el objetivo. Esta asociación puede llevar a retomar la hipótesis de la biofilia ya que al parecer este grupo siente una afiliación positiva hacia los entornos naturales. No obstante, cabría la pregunta sobre qué pasa con el grupo de los denominados urbanos. Siguiendo las explicaciones de la biofilia, se habla de que dicha afiliación puede ser en dos sentidos, una positiva de cuidado y protección hacia el entorno natural, pero también negativo el cual nos permite protegernos de los riesgos que pueden existir en la naturaleza (Wilson, 1999). Sin embargo, el grupo denominado urbano no solo respondió con emociones negativas a imágenes que pudieran resultar amenazantes sino también hacia las imágenes que se pudieran considerar positivas. Este aspecto abre la oportunidad de seguir explorando este fenómeno, ya que al menos en la presente investigación no se puede confirmar, pero tampoco refutar dichas concepciones de la biofilia.

Los datos obtenidos, en especial las que se refieren a ver las imágenes de naturaleza de paisajes con flores, montañas, etc. con una connotación negativa sugieren indagar sobre cuál puede ser el motivo de este fenómeno, ya que en otra investigación de facilitación unimodal 
se presentaron resultados similares (Sánchez et al., 2013). De entrada en el diseño se tuvo el cuidado de que todos los sujetos pasaron por las mismas condiciones experimentales. Se utilizaron los mismos estímulos, tanto facilitadores como objetivos, para todos los sujetos y además de utilizar las mismas combinaciones. Es posible que este fenómeno se pueda deberse a que en la muestra de estudio un grupo de participantes estuvo expuesto a situaciones en las cuales percibiera como negativa a la naturaleza. También se puede pensar que han pasado la mayor parte de su vida en entornos urbanos y no han podido experimentar de primera mano espacios naturales, provocando que no tengan un concepto emocional claro sobre ella, corroborando lo que plantea Sánchez y colaboradores.

Sin embargo, algo que se puede afirmar es que la técnica de facilitación afectiva en su modalidad cruzada es capaz de determinar diferentes tipos de valencia emocional hacia imágenes de naturaleza. Haciendo de esta técnica una herramienta de evaluación que permite realizar estudios de diseños arquitectónicos en donde sería útil saber de antemano cuáles serían las emociones que desencadena una cierta distribución de espacios en alguna planeación urbana, construcción habitacional o laboral. Estos aspectos son importantes para mejorar la productividad dentro de espacios de trabajo (Nieuwenhuis, Knight, Postmes \& Haslam, 2014). Y en el caso del ámbito educativo, se debe retomar los aspectos positivos de la naturaleza exponiendo a los jóvenes a espacios naturales, permitiendo así que reorganicen sus redes de información incorporando asociaciones positivas hacia este tipo de ambientes.

Además, la presente investigación demostró que, al menos con la muestra con la que se trabajó, es posible disminuir la deseabilidad social, ya que con los estímulos utilizados se detectan personas con emociones positivas y negativas hacia el entorno natural, implicando que no todos poseen una actitud positiva hacia los entornos naturales. Asimismo, de acuerdo a los hallazgos de este estudio, se pudo confirmar que tanto los diseños unimodales, como de modalidad cruzada obtienen resultados similares como lo mencionan Pavio y colaboradores (1989), así como Schneider y otros (2008). 
Si bien los resultados confirman los hallazgos detectados en otra investigación, estos no pueden generalizarse hacia otras personas debido al tipo y tamaño de muestra. Por tal motivo sería conveniente aumentar la cantidad de participantes donde se involucren diferentes áreas de conocimiento y no solo de psicología. Así también, el incluir personas que no sean estudiantes y con diferentes edades permitirá plantear conclusiones más amplias.

También sería oportuno que se diseñen investigaciones que involucren mediciones tanto explícitas como diferentes mediciones implícitas, además de la utilizada en la presente, como serían las medidas fisiológicas y el análisis del movimiento ocular ante diferentes ambientes. Esto con la finalidad de obtener más datos que permitan conocer con más profundidad las reacciones de las personas hacia los diferentes entornos. Ello daría la posibilidad de mejorar las actuales políticas y programas educativos ambientales que nos lleven hacia conductas pro-ambientales, así como determinar si se siguen manifestando el mismo fenómeno en el cual algunas personas ven a la naturaleza como negativa.

Si bien los resultados obtenidos nos indican que tanto los diseños de facilitación afectiva unimodales como cruzados tienen resultados similares, hay que tomar en consideración las limitantes planteadas y seguir indagando sobre el fenómeno y no descartar ninguno de los dos diseños al momento de plantear una investigación.

\section{Referencias}

Amérigo, M., Aragonés, J., De Frutos, B., Sevillano, V. \& Cortés, B. (2007). Underlying dimensions of ecocentric and anthropocentric environmental beliefs. The Spanish Journal of Psychology, 10(1), 97-103.

Bajo, M. T. (1988). Semantic facilitation with pictures and word. Journal of Experimental Psychology: Learning, Memory \& Cognition, 14, 579-589. 
De Vega, M. (1984). Las imágenes mentales. Introducción a la psicología cognitiva (pp. 213-259). España: Alianza editorial.

Dietz, T., Stern, P. \& Guagnano, G. (1998). Social structural and social psychological bases of environmental concern. Environment and Behavior, 30(4), 450-471.

Eder, A., Hommel, B. \& De Houwer, J. (2007). How distinctive is affective processing? On the implications of using cognitive paradigms to study affect and emotion. Cognition and Emotion, 21(6), 1137-1154.

Fazio, R. H. (2001). On the automatic activation of associated evaluations: An overview. Cognition and Emotion, 15(2), 115141.

Fazio, R. H. \& Olson, M. A. (2003). Implicit measure in social cognition research: Their meaning and use. Annual Reviews Psychology, 54, 297-327.

Garza, A. V. (2009). Rachel Carson: La escritura de lo ambiental. CULCyT, 6(33-34), 49-51.

González, A. \& Amérigo, M. (1999). Actitudes hacia el medio ambiente y conducta ecológica. Psicothema, 11(1), 13-25.

Greenwald, A. G. (1990). What cognitive representations underlie social attitudes? Bulletin of the Psychonomic Sociery, 28(131), 254-260.

Hietanen, J. K., Klemettilä, T., Kettunen, J. E. \& Korpela, K. M. (2007). What is a nice smile like that doing in a place like this ? Automatic affective responses to environments influence the recognition of facial expressions. Psychological Research, 71, 539552. doi:10.1007/s00426-006-0064-4

Hietanen, J. K. \& Korpela, K. M. (2004). Do both negative and positive environmentalsceneselicitrapidaffective processing? Environment and Behavior, 36(4), 558-577. doi:1177/0013916503261391

Hernández, B., Suarez, E., Martínez-Tovisco, J. \& Hess, S. (1997). Actitudes y creencias sobre el medio ambiente en la conducta ecológica responsable. Papeles del Psicólogo, 67, 48-58. 
Klauer, K. C. \& Musch, J. (2003). An affective priming: findings and theories. En J. Musch \& K. Klauer, (Eds.), The psychology of evaluation: affective processes in cognition and emotion (pp. 7-50). New Jersey: Lawrence Erlbaum Associates Publishers.

Knight, R. \& Reidel, S. (2002). Ecological conscience. New York: Oxford University Press.

Korpela, K. M., Klemettilä, T. \& Hietanen, J.K. (2002). Evidence for rapid affective evaluation of environmental scenes. Environment and Behavior, 34(5), 634-650. doi:10.1177/0013916502034005004

Milfont, T. L. (2010). The psychological meaning of preservation and utilization attitudes: A study using the natural semantic network technique. Psyecology, 1(1), 57-70.

Moors, A., Spruy, A. \& De Houwer, J. (2010). In search of a measure that qualifies as implicit: Recommendations based on a decompositional view of automaticity. En B. Gawronski \& B. K. Payne (Eds.), Handbook of implicit social cognition (pp. 19-37). New York, EUA: The Guilford Press.

Morales, M. G. E., López, R. E. O. \& Hedlefs, A. I. (2010). La psicología de las emociones: La expresión facial como una revelación de la emoción y el pensamiento. México: Trillas.

Nieuwenhuis, M., Knight, C., Postmes, T., \& Haslam, S. A. (2014). The Relative Benefits of Green Versus Lean Office Space: Three Field Experiments. Journal of Experimental Psychology: Applied, 20(3), 199-214. doi:10.1037/xap0000024

Olivos, P. \& Aragonés, J. I. (2013). Test de asociaciones implícitas con la naturaleza: Aplicación en España del "IAT- Nature". Revista de Psicología Social, 28(2), 237-245.

Paivio, A., Clark, J. M., Digdon, N. \& Bons, T. (1989). Referential processing: Reciprocity and correlates of naming and imaging. Memory \& Cognition, 17, 163-174.

Pato, C., Ros, M. \& Tamayo, A. (2005). Creencias y comportamiento ecológico: Un estudio empírico en estudiantes. Medio Ambiente y Comportamiento Humano, 6(1), 5-22. 
Pecchinenda, A., Ganteaume, Ch. \& Banse, R. (2006). Investigating the mechanisms underlying affective priming effects using a conditional pronunciation task. Experimental Psychology, 53(4), 268-274. doi:10.1027/1618-3169.53.4.268

Sánchez, M. M. P., De la Garza, G. A. \& López, R. E.O. (2009). La identidad y la actitud hacia el medio ambiente en estudiantes de biología y psicología. Revista PsicologíaCientifica.com, 11(10). Recuperado de http://www.psicologiacientifica.com/identidadactitud-hacia-el-medio-ambiente-estudiantes.

Sánchez, M. M. P., De la Garza, G. A. \& López, R. E. O. (2010). Un estudio de mediciones de actitudes implícitas hacia al medio ambiente en estudiantes de biología y psicología: ¿Biofilia? Revista PsicologíaCientifica.com, 12(12). Recuperado de http:// www.psicologiacientifica.com/mediciones-actitudes-haciamedio-ambiente-biofilia.

Sánchez, M. M.P., De la Garza, G. A., López, R. E. O. \& Morales, M. G. E. (2012). Escala de preferencia ambiental (EPA): Una propuesta para medir la relación entre individuos y su ambiente. International Journal of Psychological Research, 5(2), 66-76.

Sánchez, M. M. P., De la Garza, G. A. \& Rangel, S. M. L. (2013). Study on the emotional valence of environmental concepts using affective priming technique. International Journal Psychological Research, 6(2), 50-58.

Schneider, T. R., Engel, A. K. \& Debener, S. (2008). Multisensory identification of natural objects in a two-way crossmodal priming paradigm. Experimental Psychology, 55(2), 121-132.

Schultz, P. W. (2002). Environmental attitudes and behaviors across cultures. En W. J. Lonner, D. L. Dinnel, S. A. Hayes \& D. N. Sattler (Eds.), Online Readings in Psychology and Culture (Unit 8, Chapter 4). Recuperado de http://www.wwu.edu/culture/ Schultz.htm

Schultz, P. W., Shriver, Ch., Tabanico, J. \& Khazian, A. (2004). Implicit connections with nature. Journal of Environmental Psychology, 24, 31-42. 
Schultz, W. \& Zelenzy, L. (2003). Reframing Environmental Messages to be Congruent with American Values. Human Ecology Review, 10(2). Recuperado de http://www.climateaccess.org/ sites/default/files/Schultz_Reframing\%20Environmental\%20 Messages.pdf

Sintov, N. D. \& Prescott, C. A. (2011). The influence of social desirability and item priming effects on reports of proenvironmental behavior. Ecopsychology, 3(4), 257-267. doi:10.1089/ eco. 2011.0043

Stenberg, G., Radeborg, K. \& Hedman, L. H. (1995). The picture superiority effect in a cross-modality recognition task. Memory and Cognition, 23(4), 425-441.

Tacáks-Sánta, A. (2007). Barriers to environmental concern. Human Ecology Review, 14(1), 26-38.

Vozmediano, L. \& Guillén, C. (2005). Escala del nuevo paradigma ecológico: Propiedades psicométricas con una muestra española obtenida a través de Internet. Medio Ambiente y Comportamiento Humano, 6(1), 37-49.

Wilson, E. O. (1999). Biophilia and the conservation ethic. En S. R. Kellert \& E. O. Wilson, (Eds.), The biophilia hypothesis (pp. 31-41). Washington, D.C. E.U.A.: Island Press / Shearwater Books.

Recibido: 16 de enero, 2015 Aceptado: 20 de febrero, 2015 


\section{Anexo A}

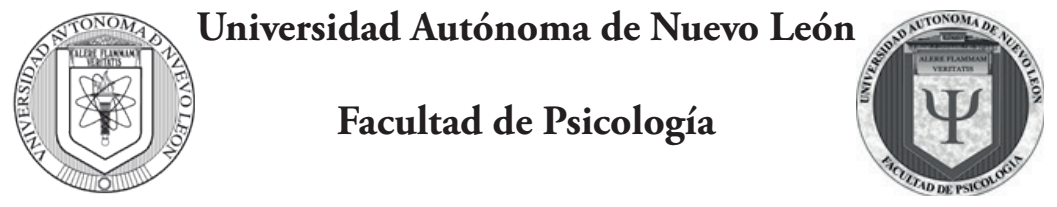

Estimado participante:

Estamos realizando una investigación que tiene como propósito evaluar la percepción que se posee de imágenes relacionadas a ambientes urbanos y naturales. El estudio consiste en la aplicación de un instrumento por medio de una computadora portátil, en cual se te mostraran imágenes de ambientes urbanos y naturales, junto a palabras con contenido emocional. El estudio tomará alrededor de 5 minutos para su realización.

Por tal motivo te hacemos la invitación a participar de manera voluntaria, y de la misma manera puedes abandonar el estudio en cualquier momento o negarte a participar sin ningún tipo de consecuencias. La información personal y los datos que obtengamos del estudios serán para uso exclusivo de la investigación y será tratada de forma confidencial.

Por tal motivo te pedimos que si estás de acuerdo en participar, lo hagas con tu nombre y firma al final de este documento. En caso de tener cualquier duda sobre la investigación, puede con toda libertad contactarnos:

Martha Patricia Sánchez Miranda

Arturo de la Garza González marpa30@gmail.com; agarza7@gmail.com; Teléfono: (52) 8183338233

Dr. Carlos Canseco \#110 y Dr. Eduardo Aguirre Pequeño,

col. Mitras Centro, Monterrey, Nuevo León, México. C.P. 64460.

Estoy de acuerdo en participar en la investigación:

Nombre Firma

Fecha 